\title{
PERFORMANCE MANAGEMENT METHOD FOR CONSTRUCTION COMPANIES
}

\author{
Namho Kim \\ Dept. of Architecture \\ Seoul National University \\ 39- 425 Seoul National University, Sillim-dong \\ Kwanak-gu Seoul, Korea, 151-742 \\ namoim7@snu.ac.kr \\ Hyun-Soo Lee \\ Dept. of Architecture \\ Seoul National University \\ 39-430 Seoul National University, Sillim-dong \\ Kwanak-gu Seoul, Korea, 151-742 \\ hyunslee@snu.ac.kr
}

\author{
Moonseo Park \\ Dept. of Architecture \\ Seoul National University \\ 39-433 Seoul National University, Sillim-dong \\ Kwanak-gu Seoul, Korea, 151-742 \\ mspark@snu.ac.kr \\ Seungjun Roh \\ Dept. of Architecture \\ Seoul National University \\ 39-425 Seoul National University, Sillim-dong \\ Kwanak-gu Seoul, Korea, 151-742 \\ rohsj97@snu.ac.kr
}

\begin{abstract}
Many companies have managed their business performance in order to achieve their enterprise purpose. Performance management which applied concept of BSC (Balanced Scorecard) is widely used all over the world. In the construction industry, BSC-based performance management is currently introduced with needs of balanced performance evaluation. However, most companies actually have intermediate level of adapting BSC. It is important to understand its process or and structure. Therefore, this paper is focused on making performance management process and defining each phase of it. In addition, the framework is established with putting them together and simulation is conducted for practical use. With developing performance process in construction, the construction companies are supposed to detect the deficiencies of the current performance management systems and take some opportunity to be helped for supporting their decision-making. In conclusion, this paper will provide the construction industry with the opportunities to enhance the values of performance management system and construction application.
\end{abstract}

\section{KEYWORDS}

Performance Management, Balanced Scorecard, Data Warehouse, OLAP, Monitoring, Search System

\section{INTRODUCTION}

In General, the company pursues multidimensional goals in terms of benefit, development, and flexibility. Flexibility means the balance between competitive objectives, decides the importance of the goals objectively and relatively. A number of companies have managed to make individual goals be coincident with organizational goals in order to maximize effectiveness against the crisis: rapidly changing business environment. To encounter this change, companies have started to bring in Performance Management, in order to accomplish organizational goals, to enhance their competitive power in the marketplace at the same time. Such effort has been continued from the traditional financial measures to Balanced Scorecard (BSC) developed by Robert Kaplan and David Norton in 1992, and still great numbers of research are on the progress. Especially, BSC performance management is in the spotlight nowadays and widely used in many companies in real. 
BSC is consisted of objectives, measures, targets, and initiatives in terms of four perspectives, financial, customer, internal business processes, and learning and growth. By using BSC, we can evaluate financial and non-financial performance at the same time. Recognizing and overcoming deficiencies of previous management approaches that used to focus on the financial performance only, BSC provides 'balanced evaluation' to adjust the strategies and policies of the company.

Construction Company conducts a number of projects at a time. In addition, several companies and other groups that concerned with the business usually participate in the project contemporarily. Due to it's limitation in nature, it is complicated to act performance management in the building industry area (Yu et al, 2004). Therefore, most of the building companies have depended on financial measures (Kagioglou et al, 2001). Acknowledging the lack of balanced evaluation and prescription of the company, major companies started to bring in the balanced scorecard to check their strength and weakness. However, construction companies are still left to be ignorant of the importance of the management using BSC. It is strongly recommended to inform the process and the system of BSC in order to maintain successful performance management.

In this research, we are going to define the process of the management, and introduce the details of each step on the process. Next, we establish framework that can lead to build a system for evaluation, and guide you to understand management steps in general. Finally, we will carry out a simulation to encourage further understanding of the actual performance management.

\section{LITERATURE REVIEW}

\subsection{Example of Performance Management Process}

A performance management is a systematic approach to improve their goals through an ongoing process of establishing strategic performance objectives; measuring performance; collecting; analyzing; reviewing; reporting performance data; and using that data (PBM SIG,
2001). In DTI of UK, they divided the process for successful application of KPIs into 7 steps shown in figure 1 and the process has applied for measuring their goals.

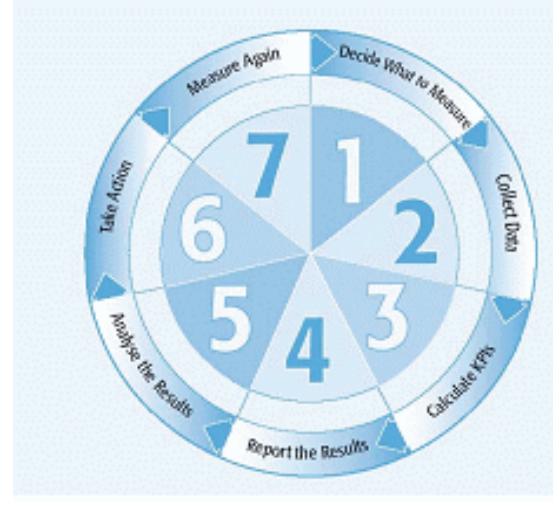

Figure 17 Basic Steps to the Use of KPIs in DTI

\subsection{Example of Performance Management in Construction Industry (1)}

Construction Industry Institute (CII) has created database from more than 1,000 projects collected from their union companies since 1996. This system gathers related data measured as five perspectives shown in table 1 from participants and KPIs. The system supplies the circumstance to companies such as benchmarking or comparing with sample project.

Table 1 Result Standard of CII

\begin{tabular}{|c|c|}
\hline & Safety \\
\hline $\begin{array}{l}\text { Cll Performanœ } \\
\text { Measurement System }\end{array}$ & $\begin{array}{l}\text { - RI.R } \\
\text { - LW.C.I.R } \\
\text { - Zero Reoordable } \\
\text { - Zero Lost Workdays }\end{array}$ \\
\hline $\cos t$ & Change \\
\hline $\begin{array}{l}\text { - Cost Growth } \\
\text { - Budget Fador } \\
\text { - Cost Fador }\end{array}$ & $\begin{array}{l}\text { - Change Cost Factor } \\
\text { - Change Schedule Factor }\end{array}$ \\
\hline Schedule & Rework \\
\hline $\begin{array}{l}\text { - Schedule Growth } \\
\text { - Duration } \\
\text { - Schedule Factor } \\
\text { - Duration Fador }\end{array}$ & $\begin{array}{l}\text { - Rework Cost Factor } \\
\text { - Rework Schedule Factor }\end{array}$ \\
\hline
\end{tabular}




\subsection{Example of Performance Management in Construction Industry (2)}

Department of the Environment, Transport and the Regions (DETR) from UK, they decide Key Performance Indicators (KPIs) for measuring their performance at the level of project and enterprise. KPIs are divided into 7 groups, and each group has indicators in detail. And each Indicator is consisted of Headline Indicators (HI), Operational Indicators (OI), and Diagnostic Indicators (DI) through their level. The cube, combined with time and supply chain dimensions, is created for multi-dimensional analysis. It is an elastic framework for making KPIs and applying in need.

\subsection{Example of Conceptual Framework of Performance Management in Construction Industry}

Kagioglou (2001) suggested concept framework according to measurement of performance in construction industry. Basically, his framework is based on the six perspectives, added perspectives of project and supplier from previous perspectives, and decides what is to be aimed and measure items of each perspective. It has been made to input the measured result and relative importance. It can get information for vision and strategy of enterprise through every perspective, measures items using input data and is able to analyze performance based on measured result within matrix.

\section{FIVE PHASE OF PERFORMANCE MANAGEMENT PROCESS}

\subsection{Measure}

Measuring phase defines the necessary perspectives for its performance management based on a concept of BSC and sets the objectives of performance. After that step, it deducts success factors, sets the target of performance and measures data with assessment of measurable index. It can add or remove new perspective in need from a criterion of standard perspectives. It is necessary to consider their weight because there would be a difference of importance among perspectives.

\subsection{Store}

In storing phase, it is a step for loading performance data into Data Warehouse (DW) and it defines fact table which contains measured data and dimension table including descriptive information about fact, and it sets the link for every table. From that, performance data schema is embodied. Data accumulated in DW has two kinds that which are measured data and converted data through extracting, refining stored data in operating system.

\subsection{Analyze}

In analyzing phase, it is a step which makes multidimensional analysis applying OLAP with performance and related data stored in DW. Most of the dimensions have the hierarchical structure. It enables to analyze the data of each level which is required by users. Next, the cube is made, after classifying hierarchical structure of dimension and setting level. The method of cube is decided according to purpose and situation of their analysis and it analyzes with slicing and dicing by preference of users.

\subsection{Report}

It is a phase of creating appropriate pages from result of previous step using table and picture without extra programming. In this step, user analyzes information through interaction with system and it displays its report to screen. When analyzing, xml formatted data which has been extracted simple information are stored in database of searching system going to be used in next step.

\subsection{Use}

This phase is used for solving problem and supporting decision-making with result from analyzed data. In case of application, by using $\mathrm{xml}$, it offers similar contents of searching result as an advertisement from searching system, and tools which offer comparable display that they can get more data and enables their role for helping reasonable decision making. 


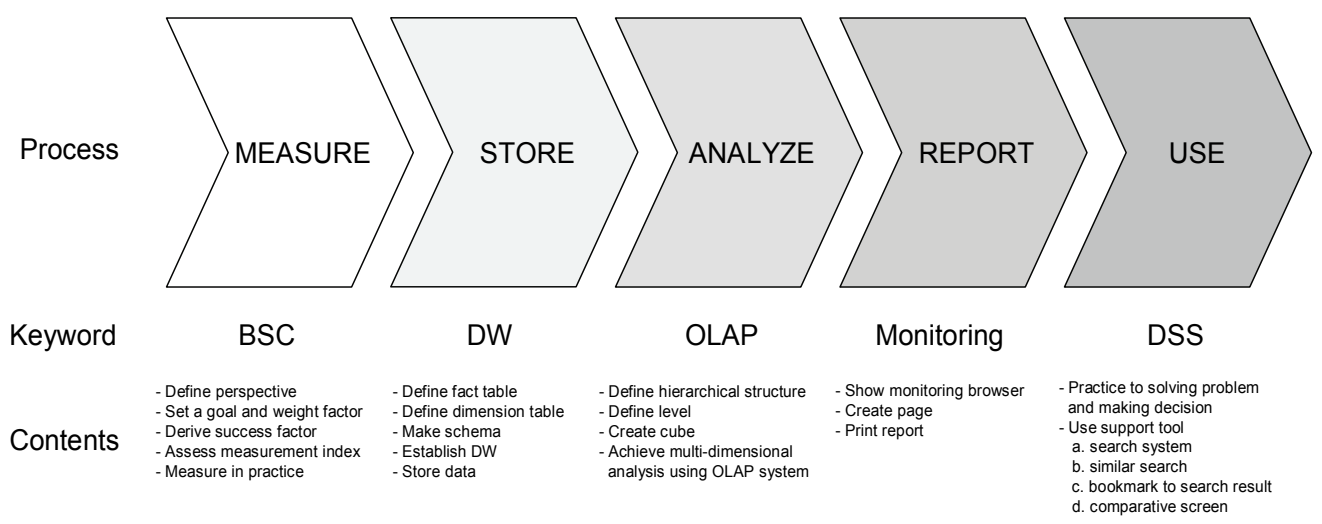

Figure 2 Performance Management Process

\section{FRAMEWORK OF PERFORMANCE MANAGEMENT}

Performance management framework is developed as shown in figure 3 .

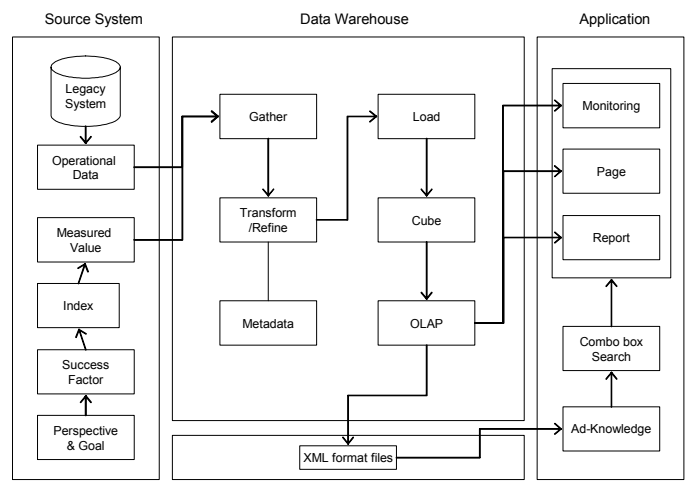

Figure 3 Performance Management Framework

\subsection{Source System}

Source system provides data, which are stored in data warehouse. It is divided into business system and measurement system. Business system. includes Enterprise Resources Planning (ERP) system, sales system, technology support system, research and development system headed by project management information system (PMIS). Measurement system is composed of several items, which are strategic goal, performance index, and measurement plan and result. Source system plays a role in inputting and saving measurement result into system on the measurement phase and selecting and preparing data needed for formation of fact table and dimension table on the store phase

\subsection{Data Warehouse}

It is important 'How to analyze and use the measured data?' as well as 'What is measured?' in management. Data warehouse is given a great deal of weight on the framework and the foundation of total system. Selected data in business system, first, is stored to DW. For that, procedure of extracting, transferring and loading (ETL) is needed. Refined data through ETL are finally stored in DW established by data schema. Next, cube is created and the table of matrix structure in order to be related between dimensions is obtained using online analysis processing (OLAP) tool.

\subsection{Application}

It presents the following applications on the framework, for providing answer of question about how to use analysis result to end-users, including experts. It shows analysis results along the several methods because users' access is restricted in the view of the composition of a screen and practical use in analysis phase. Thus, users can be experienced in report format used mainly from the past to the present, monitoring form on the screen, and web page to see on the internet. However, for the more positive performance management, method convert-ing performance results to knowledge using IT technology is selected. The method is that summary pages with $\mathrm{xml}$ structure 
are created, making of web page simultaneously and those are stored into the new database for search. This provides end-users with advertisement of similar contents, when they search for performance analysis results.

\section{SIMULATION OF PERFORMANCE MANAGEMENT}

\subsection{Source System}

In simulation, using advice of experts and literature review, it has decided its contents fits for every perspective with a concept of BSC shown in table 2. About planning data and result data, it made to get the estimated analysis results by inputting intended data, not real data.

Table 2 Performance Index in Performance Management

\begin{tabular}{|c|c|c|c|c|}
\hline Perspedive & Goal & Index & Pan & Pesit \\
\hline \multirow{2}{*}{ Finandal } & $\begin{array}{c}\text { Maximum } \\
\text { benefits }\end{array}$ & $\begin{array}{l}\text { adieverrent ratio of } \\
\text { sales }\end{array}$ & $\begin{array}{c}100 \% \\
(\$ 86,730)\end{array}$ & $\begin{array}{c}109.2 \% \\
(\$ 94,680)\end{array}$ \\
\hline & $\begin{array}{l}\text { Peduce the } \\
\text { termof work }\end{array}$ & $\begin{array}{l}\text { the days required or } \\
\text { plaaing concrete }\end{array}$ & 4days & 4.4days \\
\hline \multirow{3}{*}{ astarer } & \multirow{2}{*}{$\begin{array}{c}\text { Image } \\
\text { improvenert }\end{array}$} & $\begin{array}{l}\text { rate of solutions of public } \\
\text { grievance }\end{array}$ & $100 \%$ & $100 \%$ \\
\hline & & $\begin{array}{l}\text { rate of voluteer adivity } \\
\text { around the projed site }\end{array}$ & $100 \%$ & $95 \%$ \\
\hline & $\begin{array}{l}\text { astomer } \\
\text { satisfadion }\end{array}$ & $\begin{array}{l}\text { rate of arswer in 1:1 } \\
\text { irternet service }\end{array}$ & $100 \%$ & $80 \%$ \\
\hline \multirow{4}{*}{$\begin{array}{l}\text { Irternal } \\
\text { process }\end{array}$} & $\begin{array}{c}\text { Srengthen } \\
\text { adievernert } \\
\text { ability of work }\end{array}$ & $\begin{array}{l}\text { adieverrert ratio of } \\
\text { schedue }\end{array}$ & $100 \%$ & $98 \%$ \\
\hline & Safety & $\begin{array}{l}\text { rate of conversion } \\
\text { acidert }\end{array}$ & 0.35 & 1.26 \\
\hline & Enirormert & $\begin{array}{l}\text { the number of indication } \\
\text { thougha spot dredk }\end{array}$ & Under 3 & 3 \\
\hline & Quality & quality level & Level 3 & Level 3 \\
\hline \multirow{3}{*}{$\begin{array}{l}\text { Imovation } \\
\text { and learning }\end{array}$} & \multirow{3}{*}{$\begin{array}{l}\text { Srengthen } \\
\text { capability }\end{array}$} & $\begin{array}{l}\text { amourt of human } \\
\text { resaurces }\end{array}$ & 10 & 10 \\
\hline & & $\begin{array}{l}\text { the number of sharing } \\
\text { knowledge }\end{array}$ & 30 & 35 \\
\hline & & $\begin{array}{l}\text { rate of educationand } \\
\text { training }\end{array}$ & $100 \%$ & $110 \%$ \\
\hline
\end{tabular}

\subsection{Data Warehouse}

In order to saving data into data warehouse, the matrix of data warehouse has been established. First, define fact table and dimension table shown in figure 4. Next, it makes data schema which sets relationship of each table. Each table makes data schema for setting their relationship, looking figure 4, you can see many of dimension tables are linked with fact table as their middle and database is made from those tables. In simulation, selected data in business system (summary of project, work process, activity, material, manager and subcontract) has been stored by method of ETL under actual database. Cubes are manufactured referring data schema for real data analyzing. However, relate to the fact of fact table every dimension don't have meaning so hyper cube method is used, than multi cube method. Hyper cube method connects dimensions related to every fact. So it can be created many cubes, not one cube. Next, it analyzes using OLAP tool and it shows performance of achievement ratio of sales in financial perspective by work process and by date.

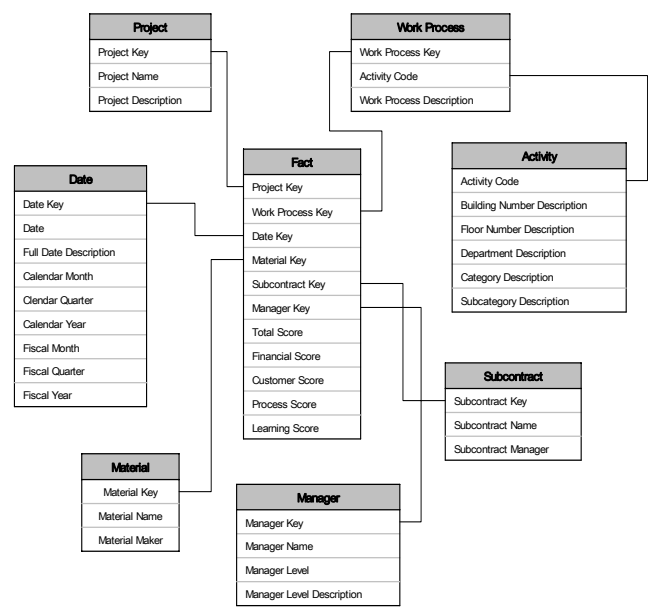

\section{Figure 4 Data Schema Included Fact and Dimension Tables}

\subsection{Application}

In this simulation, it is analyzed in the financial perspective and it shows as report format, monitoring and web page. With offering analyzed data like the format, it creates $\mathrm{xml}$ format data and stores to database for searching system. Xml format data contains basic information of project and title of query and helps to find out analyzed data with ease and detail through searching system. In simulation, it displays financial score by structural work of project $A$ and by $1^{\text {st }}$ period in 2006 using form of combo box. Similar search for that simulation shows financial score by $1^{\text {st }}$ period in 2007 by brick work of project $\mathrm{A}$, and financial score by $2^{\text {nd }}$ period in 2006 by structural work of project A. It can help to support its decision making with re-analyzing comparable data checking above contents. Users can also bookmark 
searching contents in need and show many kinds of analyzed data in one display for their convenience. Through this application, we can expect the high application rate of performance management. The final display of this application is planning to launch in web circumstance. It shows prototype of for final display in figure 5 and it is supposed to improve through more research and development.

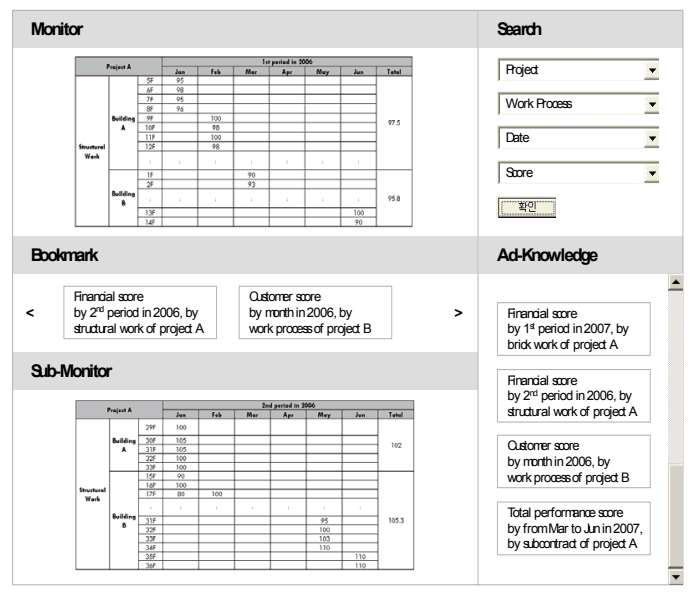

Figure 5 ProtoType of Performance Management

\section{CONCLUSIONS}

We focused on the positive performance management at the project level, and proposed a framework based on contents of each step in performance management process. In addition, we carried out a simulation to know how performance managements are performed at the project level.

In the suggested method, performance management process is the most important thing to be considered, and the following actions are achieved; performance indexes are measured for performance management in measuring phase and data are accumulated to one place for analyzing measured performance in store phase. Fact and several dimensions are existed and multidimensional analysis is achieved in analyzing phase and screen, page and report so as to show the result to user is provided in reporting phase. Last, objective and comparable data is obtained by a lot of tools and applications are used practically for supporting decision-making in using phase. This paper has made a contribution to definition of process and framework, and experiment of efficient performance management's possibility. However, it needs verification of actual situation with real data for practical use. Therefore, actual example applied with construction is presented and further research establishing system is required.

\section{ACKNOWLEDGMENTS}

This research was supported by a grant (05CITD05-01) from Construction Technology Innovation Program funded by Ministry of Construction \& Transportation of Korean government.

\section{REFERENCES}

[1] H. A. Bassioni, A. D. F. Price, and T. M. Hassan. (2004) Performance measurement in construction, Journal of Management in Engineering, ASCE, Vol.20, No.2, 42-50.

[2] Kagioglou, M., Cooper, R., and Aouad, G. (2001) Performance management in construction: a conceptual framework, Construction Manage-ment \& Economics, Vol. 19, No.1, 85-95.

[3] Kaplan, R. S., and Norton, D.P. (1992) The balanced scorecard - Measures that drive performance, Harvard Business Review, Vol.70, No.1, 71-79.

[4] Kimball, R. et al. (1996) The data warehouse toolkit, John Wiley \& Sons.

[5] U.K. DTI: Department of trade and industry. (2005) Construction products industry key performance indicators handbook, CPI KPI.

[6] U.K. DETR: Department of environment, transport and the regions. (2000) KPI report for the minister for construction, KPI Working Group.

[7] Yu, I. (2004) A Framework of the Comparable Performance Measurement in the Construction Industry, Korea Journal of Construction Engineering and Management, Vol.5, No.5, 172182.

[8] Yu, J. (2005) Development of Performance Analysis System for Construction Projects Using Data Warehousing Technology, Korea Journal of Construction Engineering and Management, Vol.6, No.1, 89-98.. 